\title{
Immunization practice in the United States and Great Britain: a comparative study
}

\author{
DAVID T. KARZON* \\ M.D. \\ Professor of Pediatrics, Professor of Microbiology \\ State University of New York at Buffalo, Buffalo, New York, U.S.A.
}

\begin{abstract}
'Epidemics that used to be excused as acts of God are now not excused as the results of the inactivity of man. In short, the incidence of many diseases has been moved from the area of chance to the area of choice. That is a vast change intellectually. Not only intellectually but also morally, for such a series of accomplishments leaves us with a new system of ethics to devise, somewhat as the perfection of the automobile has called for new traffic laws. As physicians we cannot evade a moral responsibility that goes with our newly acquired power. Having learned how disease comes about, we find ourselves answerable for why it should occur at all' (Gregg, 1949).
\end{abstract}

THE EFFECTIVE control or eradication of many infectious diseases through prophylactic immunization stands as one of the more dramatic success stories of modern medicine. The number of diseases amenable to prevention is increasing in recent years, and new developments on the horizon may be expected to further compound the already complicated immunization schedule. We have arrived at the point where, from infancy through young adulthood, the individual will receive a formidable array of biological products for the prevention of disease on a routine basis. Decisions concerning the optimal use of immunizing agents have attained a high degree of sophistication, stemming from a number of very real factors. Expert opinion has been divided on many issues. Matters of fine judgment and public policy are involved. Thus, the individual practitioner or public health officer finds that he must become learned in such areas as: the relative merits of inactivated versus live attenuated virus vaccines; the effect of adjuvants; the optimal sequence and interval of administration; the efficiency and safety of available products; the identification of high risk groups to be singled out for special immunization schedules; the contraindications to administration of individual products; the attributes of newlyintroduced biologicals and weighing of risk of disease against the risk of the immunizing procedure; the legitimacy of universal immunization against a

* Present address: Professor and Chairman, Department of Pediatrics, School of Medicine, Vanderbilt University, Nashville, Tennessee, 37203, U.S.A. disease which is absent or uncommon in the population; and the problems of simultaneous administration of immunizing agents, especially one or more live products.

Final judgment on the safest and most effective procedures to use for the immunization of the individual, community or nation rests on a complex balance of factors. More and more, the individual practitioner and the public health authorities have looked for guidance from expert national bodies. This guidance in recent years has been based increasingly on pre-designed studies such as vaccine field trials, surveillance of disease morbidity and mortality, sero-epidemiology, and surveillance of the untoward effects of vaccines. These data are then weighed against the practicalities of scheduling such immunizations within the existing patterns of delivery of health care.

The present article is an attempt to explore some of the problems and solutions undertaken in the field of immunization practice in the United States and Great Britain. A very limited review in the two countries has shown that, despite the disparate systems of delivery of health care, similar trends in immunization practice have developed. Furthermore, the rate of use of various products and their effectiveness in reduction of disease again shows more resemblances than differences. One conspicuous parallel development in the United States and Great Britain has been the increasing emergence of unified national policy concerning the use of biological reagents for immunoprophylaxis. The recommendations of national bodies, representing the consensus of informed opinion, have been powerful forces in the use of immunizing agents. These developments can be briefly traced in each country.

In the United States, one of the early influences has been the Committee on the Control of Infectious Diseases, a standing committee of the American Academy of Pediatrics. The first edition of their report, covering eight pages, was published in 1938. The current fifteenth edition, published in 1966, is a 185-page desk reference which reviews recommenda- 
tions concerning prevention of most of the infectious diseases encountered in North and South America (American Academy of Pediatrics, 1966). The report has been translated into Spanish. Through the years, the red-covered report, referred to as 'The Red Book', has become the veritable bible for the practitioner caring for children, as well as a reference point for public health authorities and well-baby clinics

During the early years of the introduction of poliovirus and measles vaccines, the United States Public Health Service issued recommendations through expert committees assembled on an ad hoc basis. To meet the need for evaluation of new and old vaccines on a continuing basis, the Advisory Committee on Immunization Practices was created in 1964. This committee was charged with apprising the Surgeon-General of the status of diseases for which effective vaccines are available, and to advise regularly on immunization practices relevant to these diseases in public health and preventive medical practice in the United States. The committee was further charged with encouraging investigation of vaccine usage and disease surveillance. Since its inception, the committee has issued formal statements on most of the major vaccines, updating these statements as new information emerged. The Advisory Committee relies heavily on the staff of the National Communicable Disease Center (NCDC) for program assistance. The NCDC has recently published a volume, Immunization Against Diseases, 1966-67 (United States Public Health Service, 1967), which includes current epidemiological reviews of selected infectious diseases, a summary of immunization status and use of biologicals in the United States, and the complete reports of the Advisory Committee recommendations.

Another potent factor in increasing the utilization of vaccines in the United States has been the trend at the state level to require certain immunizations prior to school entry. Since February 1968, half of the states required immunization against one or more diseases, including twelve which require measles, sixteen poliovirus, thirteen diphtheria-tetanuspertussis and twenty-one smallpox vaccines (United States Public Health Service, 1968a). These compulsory immunization laws are prosecuted with various degrees of conviction in different parts of the country, although exemptions are usually granted when immunizations are contrary to religious beliefs or medically contraindicated. It would appear that the trend to increasing compulsory immunization will continue, insuring that children are adequately immunized in this captive manner when entering this critical time of increased risk.

In 1962, Congress passed the Vaccination Assistance Act, which provided financial assistance to state and local health departments for improvement of immunization programs. Funds were made available for purchase of vaccines for immunization of pre-school children, support of the organization and administration of immunization programs, improvement of laboratory and epidemiological surveillance, and promotional and educational activities. Although the bulk of the support has emphasized public health and community-based programs, it has been observed in most areas that the balance between immunizations given privately and publicly does not change when a community accelerates its immunization activities (Freckleton, 1967). Appropriations for the program have ranged from 8 to 10 million dollars a year. At present there are forty-eight state and twenty-four local grantassisted programs, covering approximately $90 \%$ of the population of the United States, Puerto Rico and the Virgin Islands. By design, the program has permitted a high degree of flexibility of administration to adapt to local needs.

Another dimension that bears on the final 을 efficiency of immunization programs has become evident in the United States. There are wide differences in the rates of immunization in various demographic groups in the population. For example, vaccine acceptance has been particularly poor io the poverty areas of the large cities in the United States, especially among the Negro populationThis has also been true in certain rural regions where poverty and other special cultural factors may prevail. Such under-immunized groups often have a higher incidence of preventable diseases and in turn have been the target for intensive immunization campaigns. Specific examples of this phenomenon will be pointed out under individual diseases.

In Great Britain, over the past 20 years, there has been increasing guidance concerning immunization policy from the Ministry of Health. In 1948, when the National Health Service Act was established, smallpox vaccination and diphtheria immunization were the only officially recommended procedures in England and Wales (Ministry of Health, 1964). Pertussis immunization was undertaken by some local health authorities. BCG vaccination was later introduced to school children on a discretionary basis. Various alternative schemes for immunization with diphtheria, pertussis and tetanus were recommended in 1954 (Ministry of Health, 1955). Official schedules of combined vaccines were prepared in 1961 and adopted by local health authorities. Special committees dealing with matters such as diphtheria toxoid and poliomyelitis vaccine were superceded in 1962 by a Joint Committee on Vaccination and Immunization appointed by the Central Health Services Council and the Ministry of Health, to 'advise the Health Ministers on all the medical 
TABLE 1. Recommended schedules for routine immunization

\begin{tabular}{|c|c|c|c|c|c|c|c|c|c|c|}
\hline \multicolumn{5}{|c|}{ United States* } & \multicolumn{6}{|c|}{ England and Wales $\dagger$} \\
\hline Age & DTP & OPV & $\mathbf{M}$ & SP & Age & DTP & OPV & $\mathbf{M}$ & SP & BCG \\
\hline $2-3$ months & $\begin{array}{l}X \\
X\end{array}$ & $\mathrm{X}$ & & & 3-6 months & $\mathbf{X}$ & $\mathrm{X}$ & & & \\
\hline 4-5 months & $\mathrm{x}$ & $\mathrm{X}$ & & & 5-8 months & $\mathrm{X}$ & $\mathrm{X}$ & & & \\
\hline $\begin{array}{l}12-18 \text { months } \\
12-24 \text { months }\end{array}$ & $\mathrm{X}$ & $\mathrm{X}$ & $\mathrm{X}$ & $\mathrm{X}$ & $\begin{array}{l}9-14 \text { months } \\
12-24 \text { months }\end{array}$ & $\mathrm{X}$ & $\mathbf{x}$ & $\mathbf{X}$ & $\mathbf{X}$ & \\
\hline $\begin{array}{l}\text { School entry } \\
\text { (3-6 years) }\end{array}$ & $\mathrm{X}$ & $\mathrm{X}$ & & $\mathbf{X}$ & $\begin{array}{c}\text { School entry } \\
(3-6 \text { years }) \\
10-13 \text { years }\end{array}$ & Td & $\mathrm{X}$ & & $\mathbf{X}$ & $\mathbf{x}$ \\
\hline Every 10 years & Td & & & $\mathrm{X} \ddagger$ & School leaving & $\mathrm{Td}$ & $\mathbf{x}$ & & $\mathbf{X}$ & \\
\hline
\end{tabular}

DTP, Diphtheria-tetanus-pertussis vaccine; OPV, oral poliovaccine; $M$, measles vaccine; SP, smallpox vaccine; Td, tetanusdiphtheria toxoid, adult type.

* Adopted from United States Public Health Service (1967): Immunization Against Disease 1966-67 (National Communicable Disease Center publication).

$\dagger$ Adopted from Ministry of Health (1968a,b).

$\ddagger$ For high risk groups, i.e. health personnel and overseas travel-every 3 years.

aspects of vaccination and immunization'. Suggested schedules were published in 1963 in a booklet entitled Active Immunization Against Infectious Disease (Ministry of Health, 1963). This Joint Committee has the same general mission as the United States Public Health Service Advisory Committee on Immunization Practices.

Schedules for those immunization procedures recommended for all children are shown in Table 1 . The table has been constructed using the most recent statements available from the United States Public Health Service and the Ministry of Health (United States Public Health Service, 1967; Ministry of Health, 1963, 1968a). It is notable that the schedules are remarkably similar, despite the fact that, historically, there have been differences in the approach to the use of individual vaccines. There are several points of difference. DTP combined antigen is recommended at an earlier age in the United States, and three doses are administered in the primary series to make up for the handicaps of immaturity and maternal antibody. In the schedule recently recommended for Great Britain, initiation of immunization at approximately 6 months is favoured. This is an effort to avoid the immunological handicap and also to lessen the risk of reactions to pertussis vaccine thought to be more common in children under 6 months. A booster dose of pertussis vaccine is included in the United States schedule because of the continued threat of disease beyond infancy and the apparently more benign experience with reactions. BCG is not used routinely in schoolaged children in the United States, but is reserved for selected individuals considered to be at high risk. An additional dose of oral poliovaccine recommended at school-leaving in Great Britain is thought to be unnecessary in the United States.

\section{Status of individual diseases}

Certain diseases for which immunoprophylaxis is available will be discussed in further detail. Information concerning immunization rates, morbidity and mortality, and other problems related to vaccine use, have been gathered from a variety of sources. Except when noted, all British data refer to England and Wales. In looking at the statistical data, it is useful to remember that the population of the United States, 196 million, is approximately four times that of England and Wales, 48 million (1966). In attempting to assemble comparable data for the United States and Great Britain, it was immediately evident that a strict comparison of the use of vaccine or disease incidence was not possible because of inherent differences in notification of disease, surveillance methods, and book-keeping procedures. Despite this, many instructive comparisons can be drawn between practices in the two countries.

\section{Diphtheria, tetanus and pertussis}

The three diseases may be discussed profitably under one heading, because of the current general practice of immunization with combined antigens. Table 2 shows the percentage of children in the United States who had completed a primary course in DTP in 1966. Approximately $83 \%$ of school-aged children have received at least three, and $65 \%$ have received four or more, doses of vaccine. The difference in rates between white and non-white populations is striking at all ages, but is most marked in the younger age groups. Immunization rates for a primary series of diphtheria and pertussis in England and Wales were similar to those in the United States for the first 2 years of life. The somewhat lower percentages of children under 5 or under 16 who were 
TABLE 2. Immunization rate (\%), combined diphtheria and tetanus toxoids and pertussis vaccine (1966)

UNITED STATES

\begin{tabular}{cccc}
\hline \multirow{2}{*}{$\begin{array}{c}\text { Age } \\
\text { (years) }\end{array}$} & \multicolumn{3}{c}{ Diphtheria-tetanus-pertussis* } \\
\cline { 2 - 4 } & Total & White & Non-white \\
\hline 1 & 69 & 74 & 44 \\
2 & 74 & 78 & 52 \\
3 & 76 & 79 & 56 \\
4 & 79 & 82 & 60 \\
$1-4$ & 74 & 79 & 53 \\
$5-9$ & 83 & 86 & 70 \\
\hline
\end{tabular}

ENGLAND AND WaLES

\begin{tabular}{ccc}
\hline $\begin{array}{c}\text { Age } \\
\text { (years) }\end{array}$ & Diphtheria & Pertussis \\
\hline $1 \dagger$ & 73 & 72 \\
$2 \dagger$ & 76 & 74 \\
Under $5 \ddagger$ & 68 & \\
Under 16 & 52 & \\
\hline
\end{tabular}

* Three or more doses of vaccine (United States Public Health Service, 1967).

+ Primary series (Ministry of Health, 1967a).

¥ Percentage of children under 5 years or 16 years that 'may be regarded as remaining protected against diphtheria) (Ministry of Health, 1967a).

regarded as protected against diphtheria would represent children who had not received appropriately timed booster doses. Data were not available to the author regarding rates of tetanus immunization in England and Wales, but the magnitude can be assumed to be of the same order as that for diphtheria and pertussis. Immunization rates are far from uniformly distributed within each country. For example, while $74 \%$ of the children between 1 and 4 years of age received DTP in the United States, sections of the country varied considerably in their rates. In the New England region, $81 \%$, and in the west south-central region, $66 \%$ had received three or more doses of DTP. Rates of 91 and $92 \%$ for both diphtheria and pertussis immunization in the 1st and 2nd years of life, respectively, attained in West Sussex, were well above the general rates for England. West Sussex has instituted an automatic data-processing procedure to permit an intensive follow-up of all infants (Ministry of Health, 1967a).

There are several factors which historically have delayed the enthusiastic endorsement of combined triple antigen early in infancy, especially in Great Britain. The use of DTP received a temporary setback as a result of reports such as that prepared by the Medical Research Council in 1956, which drew attention to the increased risk of provoking poliomyelitis with such injections (Ministry of Health 1964). The virtual disappearance of poliovirus from the community largely discounted this objection. However, until recently, it was recommended that triple antigen be separated from oral poliovaccine by 3 weeks (Ministry of Health, 1963). This in itself has complicated the orderly scheduling of immunization and required an increased number of visits. Concern has been expressed regarding the number of important reactions (e.g. shock, neurological damage) accompanying the pertussis component of the combined antigen, and this type of event is said to occur more frequently under the age of 6 months. Similar alarming suggestions concerning the high rate of neurological complications in Sweden have been reported (Ström, 1960). In the United States, reactions to triple antigen administered in the first 6 months of life as a routine measure have resulted in very few documented instances of neurological damage since 1952 , when a ceiling was placed upon the antigenic content of pertussis vaccine by the United States Public Health Service (Edsall, 1961). The suggestion has been made that the prevalent antigenic strains of Bordetella pertussis have changed in the past few years, and that recent vaccine breakthroughs in England are largely associated with serotypes not represented in the

TABLE 3. Reported cases and deaths from diphtheria, tetanus and pertussis (5 years, 1962-66)

\begin{tabular}{|c|c|c|c|c|c|}
\hline & \multirow[b]{2}{*}{ Cases/year } & \multirow[b]{2}{*}{ Deaths/year } & \multirow{2}{*}{$\begin{array}{c}\text { Case } \\
\text { fatality* }\end{array}$} & \multicolumn{2}{|c|}{ Annual rates/million } \\
\hline & & & & Cases & Deaths \\
\hline \multicolumn{6}{|l|}{ United States $\dagger$} \\
\hline $\begin{array}{l}\text { Diphtheria } \\
\text { Tetanus } \\
\text { Pertussis }\end{array}$ & $\begin{array}{r}285 \\
294 \\
12,481\end{array}$ & $\begin{array}{r}36 \\
196 \\
86\end{array}$ & $\begin{array}{l}13 \\
67 \\
0.69\end{array}$ & $\begin{array}{l}1 \cdot 5 \\
1 \cdot 5 \\
64\end{array}$ & $\begin{array}{l}0.19 \\
1.0 \\
0.44\end{array}$ \\
\hline \multicolumn{6}{|c|}{ England and Wales§ } \\
\hline $\begin{array}{l}\text { Diphtheria } \\
\text { Tetanus } \\
\text { Pertussis }\end{array}$ & 21,409 & $\begin{array}{l}1 \cdot 8 \\
28 \ddagger \\
30\end{array}$ & $0 \cdot 14$ & 443 & 0.04 \\
\hline
\end{tabular}

- Deaths per 100 reported cases.

† From United States Public Health Service (1967).

$\ddagger$ Tetanus is not reportable in England and Wales, therefore this figure probably underestimated the true incidence. (Ministry of Health, 1967a).

§ From Ministry of Health (1967a). 
vaccine (Preston, 1965). To date, there are no similar reports of antigenic shift in the United States.

The average number of reported cases and deaths from diphtheria, tetanus and pertussis for the 5-year period 1962 to 1966 is recorded in Table 3. It can be seen that the number of diphtheria cases and deaths annually per million population is somewhat higher in the United States than in England and Wales. For pertussis, the death-rate is approximately the same, although the number of reported cases appears to be relatively lower in the United States. Because the number of deaths is probably a more reliable estimate of the true incidence of disease, and there is no obvious reason to expect a different death-to-case ratio, one could postulate that there is a greater under-reporting of pertussis cases in the United States. Under-reporting of a common, frequently mild and often undiagnosed disease is not surprising for the United States, and this phenomenon appears again in the discussion of measles (see below). Fig. 1 illustrates the decline in morbidity and mortality for diphtheria in the

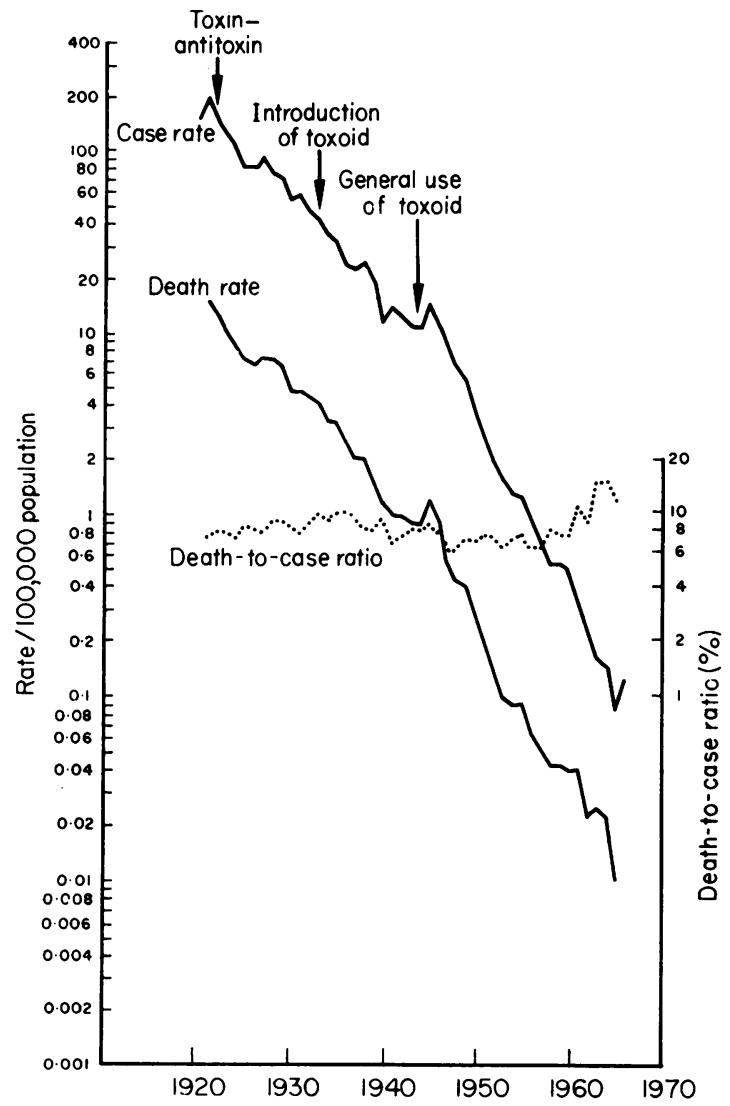

FIG. 1. Morbidity and mortality due to diphtheria in the United States, 1920-66 (United States Public Health Service, 1967).
United States from 1920 onward (United States Public Health Service, 1967). The case fatality, however, has not similarly yielded to modern therapy. The historical data on diphtheria for England and Wales available to the author would indicate a similar pattern. Fig. 2 illustrates the geographic distribution of diphtheria cases in the United States in 1966 (United States Public Health Service, 1967). Although general in distribution, the majority of the 209 cases occurred in the south-eastern states and affected primarily unimmunized segments of the population. In urban as well as rural areas, diphtheria was reported generally in lower socio-economic groups. The epidemic in Rosebud County occurred in an Indian population.

\section{Poliovaccine}

The rates of immunization with poliovaccine are shown in Table 4. Although the criteria for a primary

TABLE 4. Immunization with poliovaccine (1966)

\begin{tabular}{llcc}
\hline Age (years) & & $\begin{array}{c}\text { 3-OPV or } \\
\text { 3-IPV }\end{array}$ & $\begin{array}{c}\text { 2-OPV and } \\
\text { 0 to 2 IPV }\end{array}$ \\
\hline $\begin{array}{c}\text { United States* } \\
1-4\end{array}$ & White & 73 & 82 \\
& $\begin{array}{l}\text { Non-white } \\
\text { Total }\end{array}$ & 57 & 65 \\
England and Walest & 70 & 79 \\
1 & & 68 & \\
2 & 72 & \\
3 & 76 & \\
\hline
\end{tabular}

OPV, Oral poliovaccine; IPV, inactivated poliovaccine.

* From United States Public Health Service (1967).

$\dagger$ From Ministry of Health $(1967 a, b)$.

course of vaccine are somewhat different, the overall rates are quite comparable. In the United States, in the age group 1-4 years, approximately $70 \%$ have had either three doses of oral or inactivated vaccine and $79 \%$ two doses of oral poliovaccine. It is notable that the immunization rates are different in the white and non-white populations, reflecting the socio-economic differential in the distribution and/or acceptance of vaccine. The overall rates in England and Wales for the early years of life are very close to the United States data. The shift away from the use of inactivated poliovaccine is of interest. In 1966, less than $1 \%$ of the vaccine distributed in England and Wales was the inactivated type; in the United States, the figure was $17 \%$, compared to $20 \%$ in 1965 .

Fig. 3 (United States Public Health Service, 1967) and Fig. 4 (Miller \& Galbraith, 1965) show the dramatic decline in the incidence of poliomyelitis. In 1966, there were only nineteen cases of paralytic disease in England and Wales, a record low. The cases were sporadic, and no epidemic foci were reported. In the same year, 108 cases of paralytic disease occurred in the United States, two-thirds of 


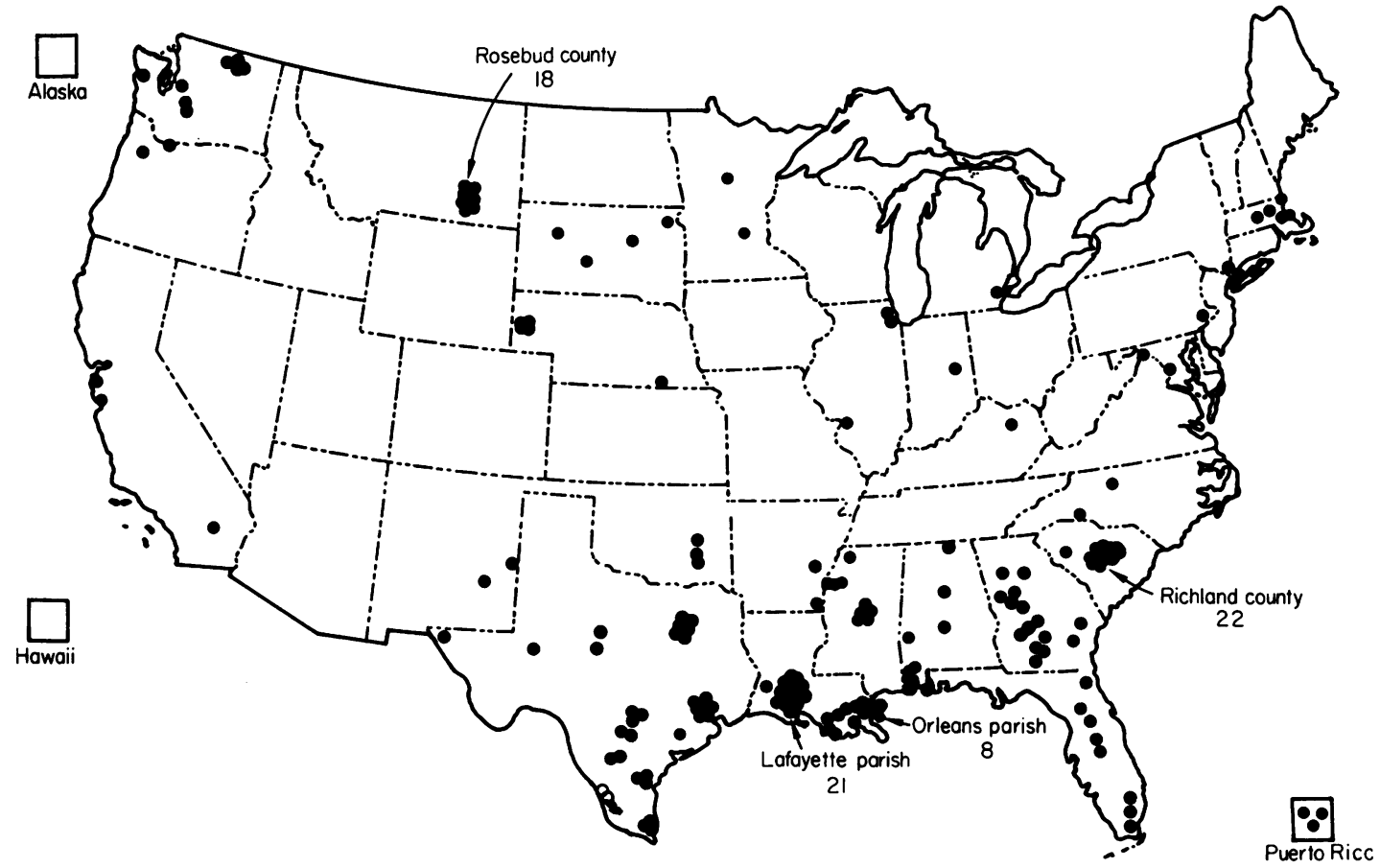

FIG. 2. Geographic distribution of reported cases (O) of diphtheria in the United States, 1966 (United States Public Health Service, 1967).

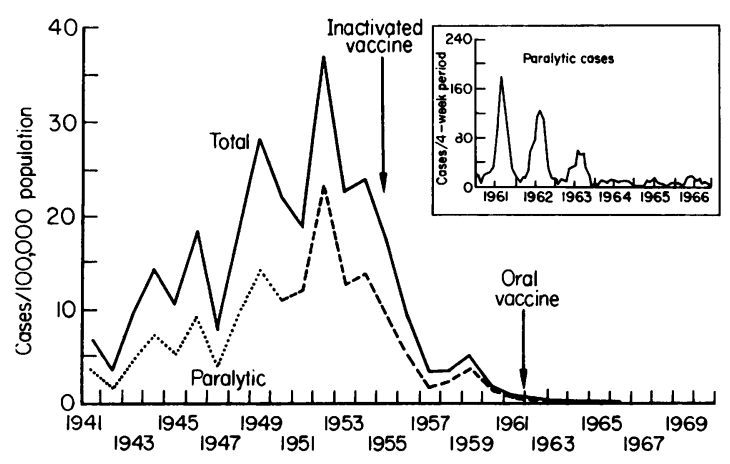

Fig. 3. Total poliomyelitis and paralytic cases reported in the United States, 1941-66 (United States Public Health Service, 1967).

which occurred in the state of Texas, where a type 1 poliovirus epidemic occurred (Fig. 5). The cases were concentrated primarily along the Mexican border. Seventy-five per cent of the paralytic cases had received no poliovaccine, and only seven cases had histories of adequate immunization. Surveillance in the United States since licensing of poliovaccines has shown that no more than one case of 'vaccinerelated' paralytic disease has occurred for every 3 million does of oral poliovaccine administered, and these have occurred largely in adult males (United States Public Health Service, 1967). In 1966, there

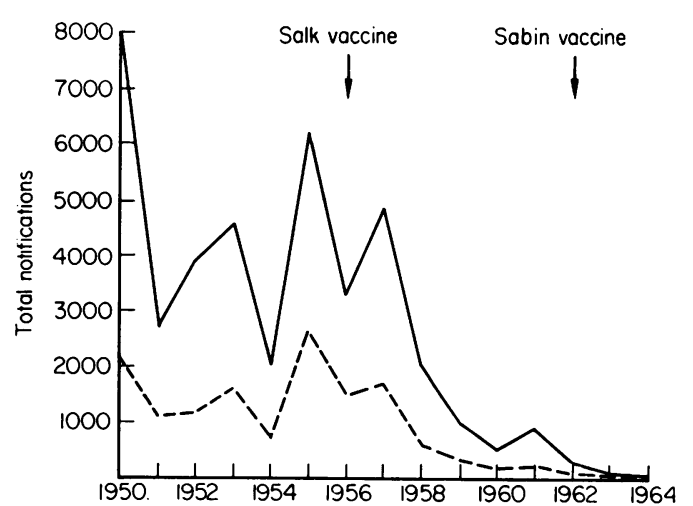

FIG. 4. Total poliomyelitis and paralytic cases reported in England and Wales, 1950-64 (Miller \& Galbraith, 1965) -, Total notifications; . . . , non-paralytic cases.

were ten possible 'vaccine-related' cases of poliomyelitis reported in the United States. One was related to the administration of inactivated poliovaccine, the other nine to oral vaccine, on the basis of the epidemiological criteria used. A similar study in England and Wales for the 3 years 1962 to 1964 revealed four cases with residual paralysis occurring between 5 and 28 days after vaccination, an incidence of one case in 4.5 million doses of live vaccine (Miller \& Galbraith, 1965). Weighing the benefits of poliovaccine against the minute risks involved, its routine use appears to be well justified. 


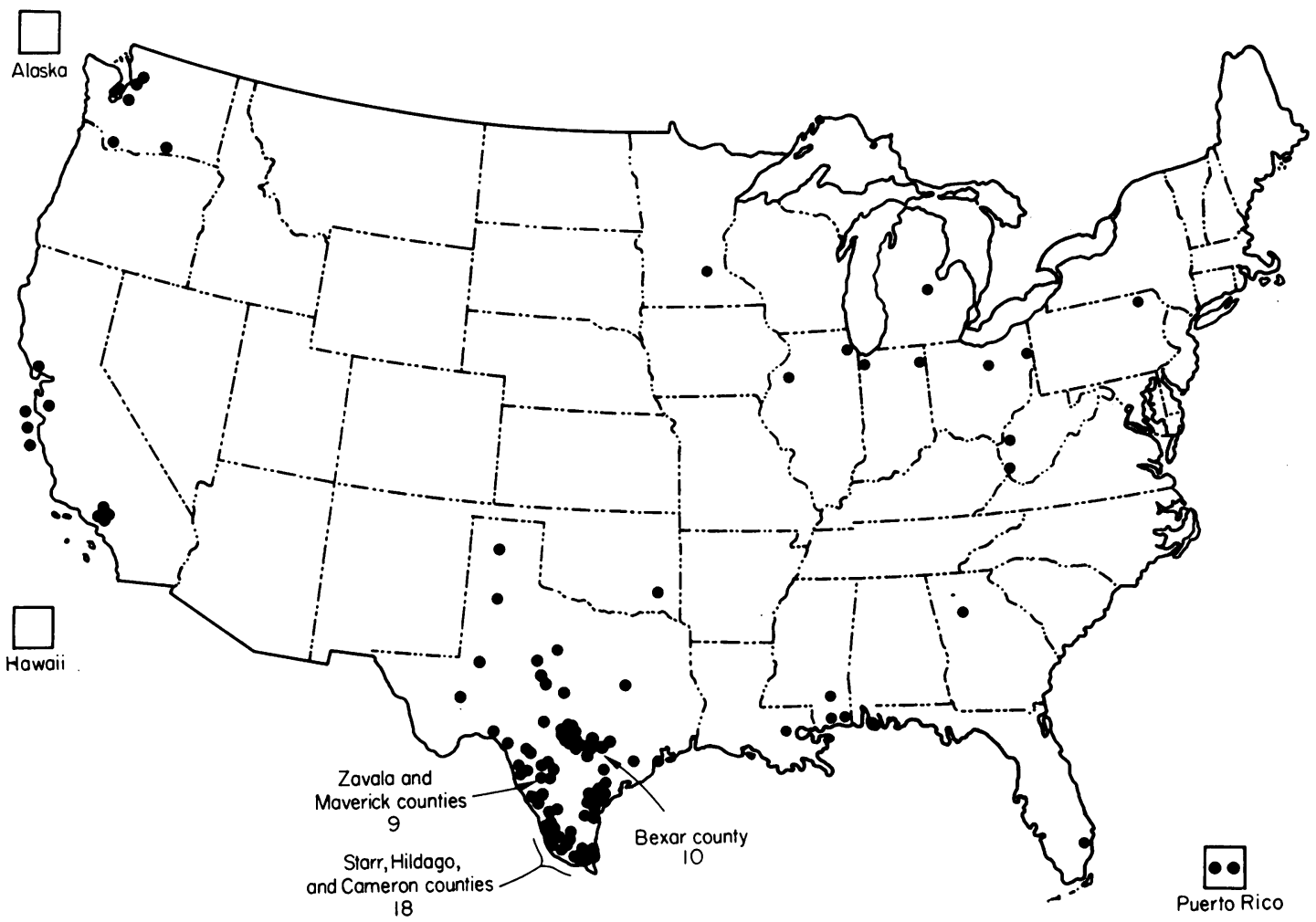

FIG. 5. Geographic distribution of reported paralytic poliomyelitis cases (O) in the United States, 1966 (United States Public Health Service, 1967).

TABLE 5. Immunization with smallpox vaccine

\begin{tabular}{llrrrrr}
\hline & & U.S.* & & \multicolumn{2}{c}{ England and Wales $\dagger$} \\
\cline { 5 - 7 } & & 1964 & & 1964 & 1965 & 1966 \\
\hline Total immunizations (thousands) & Primary & 5420 & 340 & 390 & 480 \\
& Revaccination & 7370 & & 70 \\
Per cent infants immunized 0-2 years & Unknown history & 560 & & 32 & 33 & 38 \\
\hline
\end{tabular}

* United States Public Health Service (1967).

$\dagger$ Ministry of Health (1967a).

\section{Smallpox vaccine}

Infants were immunized with smallpox vaccine at the rate of $32-38 \%$ in England and Wales in the years 1964-66. In comparison, the rate in the United States in 1964 was $57 \%$ (Table 5). Fig. 6 shows the smallpox immunization status of the population in the United States. A rate of $80 \%$ was attained by school entry, and over $95 \%$ of the population eventually received a primary vaccination (United States Public Health Service, 1967). In England and Wales, the 480,000 individuals who received primary smallpox immunization in 1966 were equivalent in number to slightly more than one-half the births for the year. In the United States in 1964, 5.4 million primary vaccinations were given, which is more than one and one-half times the number of births. In England and Wales, there were approximately 70,000 persons (1966) revaccinated, compared to 7.4 million revaccinations in the United States (1964). In the 10-year period 1951-60 in England and Wales, there was an average of 124,000 revaccinations per year. In recent years in the United States, there have been approximately 3 million individuals who have travelled overseas and received vaccinations on this account. Most of these are revaccinations. Thus, while all the data which 


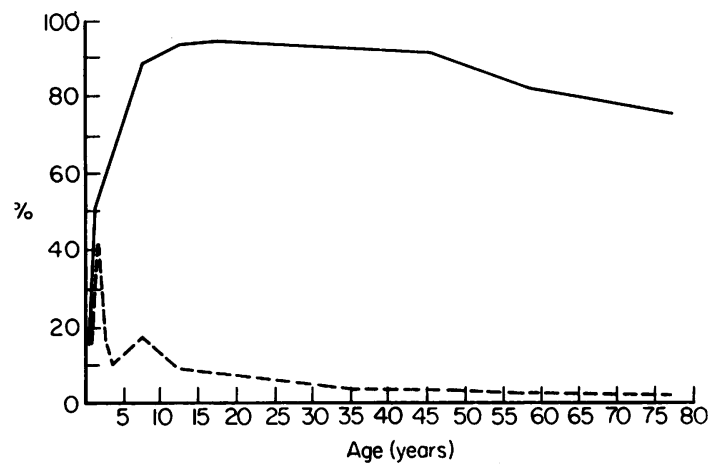

FIG. 6. Smallpox immunization status in the United States, surveyed in 1964 (United States Public Health Service, 1967). —, \% vaccinated during lifetime; . . . , \% vaccinated within past 12 months.

would be desirable are not at hand, indications are that the population of the United States is more highly vaccinated and revaccinated than that in England and Wales. However, in neither case are the rates sufficiently high to have a dependable herd immunity in face of an introduction of a case of smallpox.

In 1962, the Joint Committee on Vaccination and Immunization recommended that vaccination be performed optimally during the 2nd year of life, rather than at 4-5 months, as previously practiced (Ministry of Health, 1964). Further, it was urged that smallpox immunization be universally adopted, because it was clear that the vaccination rate for smallpox was well below that of other regular immunization procedures in infancy.

In the 10-year period 1957-66, in England and Wales, there were 142 cases of smallpox, with twenty-nine deaths, a mortality rate of $20.4 \%$ (Table 6) (Ministry of Health, 1967b). These resulted from eleven documented importations. In
TABLE 6. Smallpox in England and Wales, 1957-66*

\begin{tabular}{cccc}
\hline Year & $\begin{array}{c}\text { Known } \\
\text { importations }\end{array}$ & Cases & Deaths \\
\hline 1957 & 1 & 4 & 2 \\
1958 & 1 & 6 & 1 \\
1959 & 1 & 1 & \\
1960 & 2 & 1 & \\
1961 & 6 & 66 & 26 \\
1962 & & 62 & \\
$1963-65$ & 11 & 142 & 29 \\
1966 & & & \\
Totals & 11 &
\end{tabular}

* Ministry of Health (1967b)

1966, there were four outbreaks of Variola minor. The origins of these apparently multi-centered occurrences were not determined. Between 1961 and 1964, there were eleven instances of importation of smallpox into Great Britain, Germany, Sweden and Poland, resulting subsequently in a total of 222 cases and thirty-nine deaths before effective control was achieved (Karzon \& Henderson, 1966). In many of the introductions, half or more of the subsequent cases were in hospital personnel.

In the United States, the last major outbreak occurred in 1947 in New York City, from a case imported from Mexico. The last potential introduction occurred as recently as 1962 , when a 12-year-old boy from Brazil was admitted into the country at Kennedy Airport in New York. He departed immediately by train for Canada, where he became ill with typical smallpox shortly after arrival. Early diagnosis of the case, effective control measures, and an element of luck prevented the development of secondary cases (Karzon \& Henderson, 1966).

Deaths, as well as central nervous and dermal complications of smallpox vaccination, in various age groups are shown in Table 7. The data from

TABLE 7. Complications associated with primary smallpox vaccination

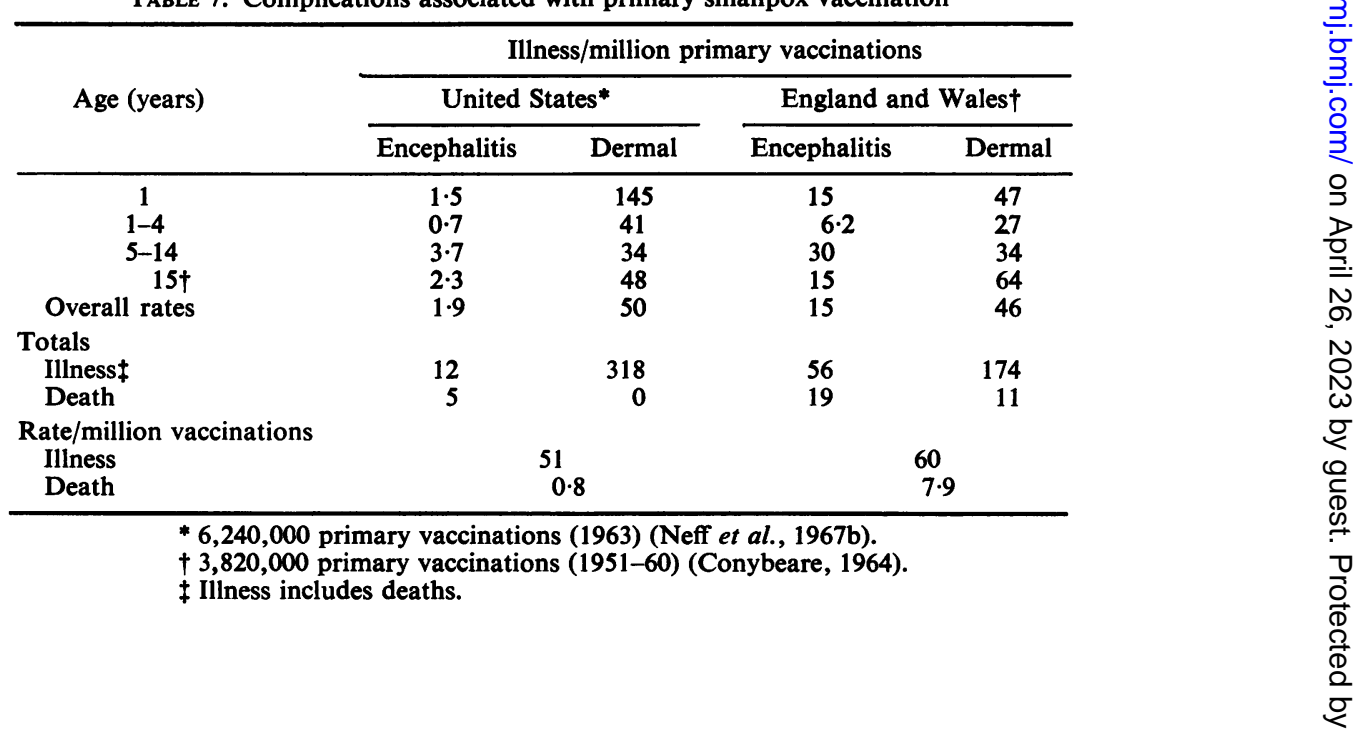


TABLE 8. Comparative rates of complications associated with primary smallpox vaccination or revaccination (per $1,000,000$ vaccinated)

\begin{tabular}{|c|c|c|c|}
\hline & \multicolumn{2}{|c|}{ United States } & \multirow[t]{2}{*}{ England and Wales $\ddagger$} \\
\hline & U.S.* & Four States $\uparrow$ & \\
\hline \multicolumn{4}{|c|}{ Primary vaccination } \\
\hline Illness & 51 & 134 & 61 \\
\hline Death & 0.8 & 0 & $7 \cdot 9$ \\
\hline \multicolumn{4}{|c|}{ Revaccination } \\
\hline Illness & $2 \cdot 2$ & 11 & 16 \\
\hline Death & 0 & 0 & $2 \cdot 4$ \\
\hline
\end{tabular}

England and Wales was reported routinely to the health authorities (Conybeare, 1964); the United States data stemmed largely from the list of patients for whom vaccinia immune-globulin had been requested, death certificates, routine reports to state health departments, and a national physician questionnaire (Neff et al., 1967a, b). Based on this crude information, the incidence of encephalitis and the overall death rate were higher in England and Wales than in the United States. However, the rate of various types of dermal complications was approximately equal. Theoretically, half to twothirds of the complications such as Eczema vaccinatum and Vaccinia necrosum may be prevented by more careful screening for known contraindications, and by delaying vaccination until after the 1st year of life. Contraindications include patients with depressed immune-response, either spontaneous or drug-induced; pregnancy; simultaneously administered live vaccines; and skin diseases, such as eczema, in the recipient or household contact. In general, there were approximately one death per million primary vaccinations in the United States, and fifty-three total complications per million. There were no deaths and $2 \cdot 2$ complications per million among 7.8 million revaccinees. In England, the death rate was somewhat less than eight per million, and the complications rate about sixty-one per million. There were 2.4 deaths and sixteen complications per million after revaccination. Thus, in both countries, revaccination was accompanied by a very small risk compared to primary vaccination (Table 8).

In another study, physicians in four states were surveyed by questionnaire concerning major and minor complications associated with smallpox vaccination. A significantly higher rate of Eczema vaccinatum and generalized vaccinia of a mild nature was uncovered. A total of 134 complications was reported per one million primary vaccinations and eleven per million revaccinations. Of the reported
279 patients with available data, only twenty-two were hospitalized (Neff et al., 1967b) (Table 8).

The incidence and mortality from central nervous complications in both England and the United States is clearly less than that reported from certain other countries. In several studies reported from the continent, rates as high as one case in 1000 primary young adult vaccinees have been documented. There is no satisfactory explanation for this significant variation in incidence, although it should be noted that different strains of vaccinia virus are employed in various countries. The recommendation to defer immunization to the second year was based upon studies of Conybeare (1964), in which it was shown that encephalitis as well as dermal complications are far more frequent under 1 year of age than in the second year of life. Similar studies in the United States have also shown an excessive risk in children under 1 year of age (Table 7) (Neff et al., 1967b).

In the United States, official policy has always been rather firm in advocating universal smallpox immunization, although this policy has been increasingly questioned (Dixon, 1962; Dick, 1962; Kempe \& Benenson, 1965). Despite the requirement for a valid vaccination certificate, the possibility of introduction of a case into the United States is a real one. This risk is constantly changing, with increasing travel, but with a decreasing reservoir of endemic smallpox. Immunization to the fullest possible extent of infants and pre-school children is a principal means for community protection against introduced smallpox. Successfully vaccinated children should be essentially wholly immune for perhaps 3-5 years, with decreasing protection for a longer period. With primary sensitization accomplished, revaccination of older children and adults is attended by a much lower frequency of complications. Should a case of smallpox be introduced and recognized, subsequent control is accomplished by quarantine and selective vaccination; mass vaccination is considered inadvisable. Partial immunity of the popula- 
tion as a result of previous vaccination offers certain advantages, in that the likelihood of spread in the community is diminished, and the antibody response to revaccination is more rapid and attains a higher titer (Ministry of Health, 1963). The value of chemoprophylaxis (methisazone) as an aid in epidemic control is not established, and the use of the drug is accompanied by a significant incidence of toxicity.

\section{Measles vaccine}

Live attenuated measles virus vaccine became available in the United States in 1963, and more than 30 million doses were distributed by the beginning of 1968 . In late 1966 , an intensive program was initiated, supported largely by the Vaccine Assistance Act, to eradicate measles in the United States. This was conducted through regular public and private immunization channels as well as through special community campaigns, the latter especially in areas with low immunization rates. Also, epidemics have been effectively aborted by the prompt administration of measles vaccine to selected groups of children, especially susceptibles in nursery school, kindergarden, and the first two or three grades of elementary school. The effectiveness of the total national effort is demonstrated in Fig. 7

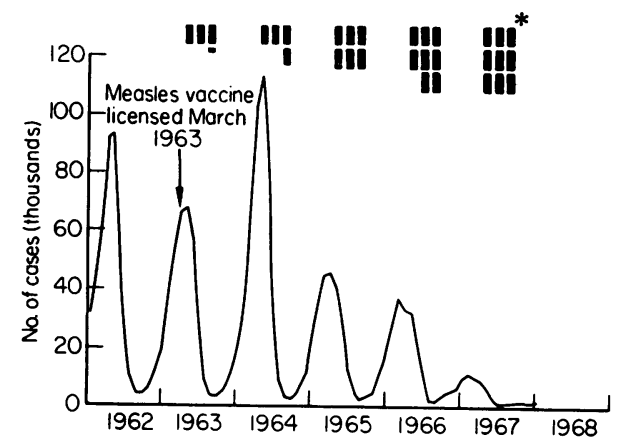

FIG. 7. Reported cases of measles in the United States, 1962-67, and distribution of live measles vaccine (United States Public Health Service, 1968a). Blocks, 1 million doses. *Estimated total for 1967.

(United States Public Health Service, 1968a). The number of reported cases of measles in 1967-68 is lower than any year since the onset of measles reporting in 1912, and is less than $10 \%$ of the expected incidence. The long-term trends are shown in Fig. 8.

A high percentage of pre-school children have now been immunized. In areas where special campaigns have been conducted, the rates are very high; for example, $94 \%$ in Los Angeles County and $91 \%$ in the state of Rhode Island. Other states reported between 50 and $80 \%$ of the pre-school population immunized at the end of 1967 (United

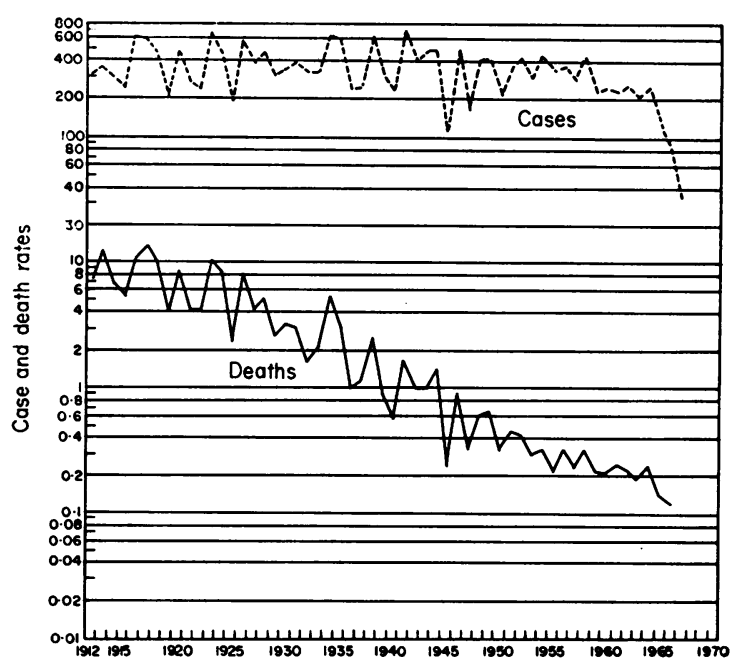

FIG. 8. Reported measles cases and deaths in the United States, 1912-67. Live measles vaccine was licensed in 1963 (United States Public Health Service, 1968c).

States Public Health Service, 1968a). Approximately thirty states report rates of $90 \%$ or more in school-aged children, a direct result of school-wideo programs (United States Public Health Service, 1968a).

Some of the factors concerning the problems of introducing a new immunizing product into the population are illustrated in a study of measles vaccine in Erie County, New York, population 1 million (Lennon et al., 1967). A survey was conducted in 1966, 3 years after the licensing of live measles virus vaccine, but prior to the launching of the intensive national effort to eradicate measles. The immunization rates reflected distribution through normal channels of health care. The survey showed that $82 \%$ of the vaccinations were received from private physicians, $15 \%$ through health department clinics and 3\% from other medical facilities, such as hospitals. There was a sharp division of the rate of immunization of susceptible children by socio-economic group. In the urban area, $73 \%$ of the upper, $57 \%$ of the middle and $19 \%$ of the lower, socio-economic group were immunized. As a consequence of these findings, an intensive campaign to immunize the lower socio-economic group in Erie County, concentrated in the core area of the City of Buffalo, was successfully instituted.

Prior to the introduction of vaccine, approximately 400,000 cases had been reported annually in the United States. Because $90-95 \%$ of all young adults have a history of clinical measles, it may be assumed that, if all cases were reported, almost 4 million 
cases should be reported per year. It may thus be calculated that somewhat over $10 \%$ of clinical cases are in fact reported. Since the introduction of measles vaccine and the initiation of more careful surveillance, the percentage of cases reported has undoubtedly improved beyond this figure. In England and Wales, a similar number, over 400,000 cases a year, are reported. On the basis of the same type of calculations, one can estimate that almost half of the cases of clinical measles are therefore reported. In recent years (prior to vaccine introduction) there have been $300-400$ measles deaths annually in the United States, and approximately 50-150 deaths annually in England and Wales. Thus, in both countries, the mortality from measles has been approximately two per million population annually.

Measles vaccine became available in Great Britain early in 1966. Clinical trials of live vaccine preceded by inactivated vaccine have indicated that a better degree of long-term protection can be expected from live vaccine alone. The untoward effects observed in the United States in children who had received multiple doses of inactivated vaccine and then, after several years, were given live measles vaccine or were exposed to natural measles have so far not been observed in Great Britain. There is a strong case for the use of live measles virus vaccine alone. The desirability of adopting a vigorous national policy for the elimination of measles was proposed by the Ministry of Health recently (1968a). All susceptible children through the age of 15 years are recommended to receive a dose of live attenuated virus. This should be given during the 2 nd year of life and not earlier than 9 months of age.

\section{Other vaccines}

Comments concerning the use of certain vaccines which are used only under special circumstances may be of interest. The status of the vaccines in the United States will be compared to that in Great Britain whenever possible.

While exposure to rabies in the United Kingdom would be exceptional, rabies is a problem of significant proportions in the United States. Fig. 9 shows the trends in animal rabies in the United States from 1953 to 1966 . Rabies in domestic animals, largely dogs, livestock and cats, has fallen sharply, while there has been an increase in rabies in wildlife, especially skunks, foxes, and bats (United States Public Health Service, 1967). However, the number of human deaths from rabies declined from thirtyfour in 1946 to one or two annually in recent years. This decline has resulted in great part from a reduction in rabies in dogs through immunization (United States Public Health Service, 1967). As prophylaxis following proven or assumed exposure, an estimated

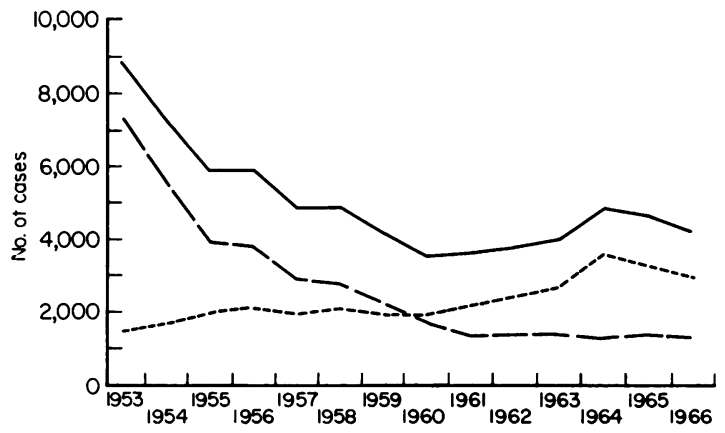

FIG. 9. Reported rabies in domestic and wild animals in the United States, 1953-66 (United States Public Health Service, 1967). —, Total; . . . , wild; - — - domestic.

30,000 persons received rabies vaccine and approximately 8000 also received anti-rabies serum in 1966.

BCG is recommended for tuberculin-negative children between the ages of 10 and 13 years, at the discretion of the Medical Officer of Health in England and Wales. In certain areas, BCG is given as a routine in infancy. On the other hand, BCG vaccine in the United States is advised only for infants or children who are at special risk of known heavy exposure to tuberculosis in their immediate environment, and, as a consequence, is used far less frequently. In England and Wales in 1966, 640,000 school children and tuberculosis contacts were skintested. Five hundred and fourteen thousand were found to be tuberculin-negative, and of these, 479,000 were vaccinated with BCG. Twenty-nine per cent of contacts and $14 \%$ of school children were tuberculin-positive. In 1966, there were approximately 15,000 tuberculosis notifications in England and Wales, or a rate of twenty-one per 100,000 population (Ministry of Health, 1967a). In the United States, there were approximately 48,000 new active cases, or a rate of twenty-four per 100,000 (United States Public Health Service, 1968b), with a low of 6.5 in North Dakota and a high of 55.5 in Alaska. At the end of 1966, there were 316,000 cases under supervision because of a tuberculous lesion in England and Wales, and at the same time there were 320,000 persons in the United States on state and local health department tuberculosis registers. There are undoubtedly significant differences in recording and classification contributing to these data, and they may not be directly comparable.

The general recommendations for the use of influenza vaccine are quite similar in the two countries-namely, for the protection of those individuals suffering from certain chronic diseases for whom influenza might prove to be an unusual medical risk. In addition, in the United States, all individuals over the age of 65 , a group in which there 
is excess mortality accompanying influenza epidemics, are recommended to have annual doses of influenza vaccine. Influenza vaccine is not recommended for general use in the population.

The live attenuated mumps virus vaccine was introduced in the United States early in 1968. Seroconversion and clinical protection have been demonstrated in field trials to last for at least 3 years, which is the longest period of follow-up. The product appears to be free of toxicity. The long-term duration of protection is under continued study. The United States Public Health Service Advisory Committee on Immunization Practices has suggested that live mumps vaccine be considered for use in children approaching puberty, in adolescents, and in adults, especially males, if they have not had mumps (United States Public Health Service, 1967). The vaccine should also be considered in certain institutional settings. The vaccine is not recommended for routine use in younger children, although it is not specifically contraindicated. The rationale for the use of mumps vaccine lies in the prevention of certain complications. Approximately $15 \%$ of reported cases of mumps occur after the onset of puberty. Orchitis has been observed in $20 \%$ or more of post-pubertal males, and other organ systems, including the central nervous system, are occasionally involved. Sequelae are uncommon, although unilateral deafness is not a rare event (Karzon, 1968a). In terms of public health priorities, the Advisory Committee has stated that mumps immunization programs should not pre-empt other public health programs of established importance. However, should observation confirm the long-term effectiveness and freedom from toxicity, it may be predicted that increasing use will be made of mumps vaccine, both in private practice and public programs.*

A live attenuated rubella virus vaccine is at the present time undergoing field trials in the United States in closed and semi-closed populations. Serconversion and clinical protection are of a high order. The attenuated virus replicates and can be recovered from the pharynx, although it does not appear to be transmissible. Studies are continuing to evaluate the safety of the rubella vaccine in the open population and in adults, before a licensed product can be made available.

\section{Simultaneous use of immunizing agents}

There are several factors which have tended to support the recommendation that administration of

\footnotetext{
* Recently, the Advisory Committee has liberalized its recommendations for mumps vaccine and suggests consideration be given to immunizing all susceptible children over 1 year of age. However, the position was reaffirmed that mumps vaccine programs should not be allowed to take priority over essential ongoing health activities. U.S. Public Health Service (1968d).
}

immunizing agents be separated whenever feasible, especially when one is a live vaccine. The bases for this recommendation are two-fold: (1) possible interference between two or more antigens, and (2) possible enhancement of toxicity. An example of the latter is the provocation effect of DTP on poliomyelitis infection. It is recommended that administration of two live vaccines be separated by 4 weeks in the United States and 3-4 weeks in England and Wales. The need for separation of antigens is causing an increasing hardship in scheduling visits of small infants. In the United States there are four live products-poliovirus, measles, smallpox and mumps -and a fifth live product, rubella, may soon be available. It is, therefore, of more than theoretical interest to determine the legitimacy of the objections which have been raised to simultaneous use of live vaccines. Studies are in progress to explore the antibody responses to multiple vaccines and possible enhancement of toxicity. If simultaneous administration were feasible, a multivalent product would be of great public health significance. The earliest schedules of vaccination and immunization procedures suggested by the Ministry of Health. In the recommended that DTP and live vaccine other than live poliovaccine be separated by 3-4 weeks. Such a restriction has not been placed in the United States, and at the present time no ill-effects have beeno documented from simultaneous DTP and live vaccine administration. Recent studies have shown that measles or yellow fever vaccine virus may depress, at least in part, the replication of a second virus, presumably on the basis of interferon production. The maximum inhibition is during the second week following administration of the first virus. Thus, the recommendation that yellow fever vaccine be given at least 4 days before primary vaccination against smallpox (Ministry of Health, 1967a) may be expected to decrease the effectiveness of the smallpox take and antibody response (Karzon, 1968b).

\section{Discussion and conclusions}

There has been a consistent downward trend in the morbidity, mortality and residua due to most infectious diseases in the developed countries of the world. Improvements in the social and economic sphere and the control of environmental human waste and arthropod vectors have played major roles. However, the widespread use of immunizing agents has notably contributed to this decline. Society is becoming increasingly expectant that preventable disease will indeed be prevented.

The present review is a modest beginning in the effort to relate official policy on immunization practice in the United States and England and Wales, and the actual use of various biological 
products, with trends in morbidity and mortality of preventable diseases. The settings for the study form an interesting backdrop. Child health practices are quite distinct in England and Wales under the tripartite National Health Service Program, when compared to the United States, where a combination of the board-certified pediatrician and the general practitioner, as well as public agencies such as the well-baby clinic and hospital outpatient department, all participate in aspects of preventive and curative medicine. Through the two different pathways, similar mechanisms for evaluation of optimal immunization schedules have evolved. Also, it is increasingly evident that the specific recommendations have drawn more closely together. There have been minor differences of emphasis. For example, the American philosophy has shown less concern with immunodepression due to maternal antibody and immunological immaturity and has regularly immunized beginning at 8-12 weeks, with combined vaccine, adding a third dose to increase efficiency of the program. In Great Britain, there has evidently been a greater concern regarding the risks of smallpox immunization, which has resulted in the lower levels of immunization attained with smallpox vaccine.

The very conspicuous disparities in immunization rates, based upon social class and reflected in low immunization rates in such areas as urban Negro ghettos and rural poverty areas, have posed one of the major residual public health problems in infectious disease control in the United States. It would be of interest to study the acceptance of various immunizing procedures by social class in Great Britain, to determine whether the freely available services may be unevenly distributed in a similar fashion, based on cultural and behavioral characteristics of population groups. For example, poliomyelitis in the United States, once a disease with relative selectivity for the upper classes with a high level of environmental and personal hygiene, is now a disease of the lower classes, in residual pockets with inadequate immunization. It has been generally observed that immunization rates in a given population bear a direct relationship to the general extent of contact between the infant and those charged with early child health care. That is, children who attend a physician only for episodic illness and do not receive regular well-baby care will have poorer immunization records. A corollary of this would state that improvement of the general level of immunization would be tied to an improvement in the general level of infant care and regularity of contact between the family and health facilities. However, the latter situation is not always simple to achieve, and more direct efforts aimed specifically at attaining higher immunization rates can be successful, both as single mass community campaigns or in some form of ongoing program.

It is hoped that the information presented and the interpretations which have resulted will be a stimulus for others to continue to study comparative immunization practices.

\section{Acknowledgments}

This paper could not have been written without the help and advice of Dr A. T. Roden of the Ministry of Health, who kindly provided much of the published and unpublished information from England and Wales. For data from the United States, I have leaned heavily on the Reports of the National Communicable Disease Center of the United States Public Health Service. In particular, I would like to thank Dr F. Robert Freckleton and Dr Alexander Langmuir and their staffs for their encouragement and for permission to use data placed at my disposal. For errors in presentation or interpretation, I lay personal claim. Morbidity and mortality information has been obtained from publications of the Ministry of Health, for which I would like to make acknowledgement to the Controller of Her Majesty's Stationery Office.

Dr Karzon is recipient of a Research Career Award (AI-1136) from the National Institutes of Allergy and Infectious Diseases, United States Public Health Service.

\section{References}

American Academy of Pediatrics (1966) Report of the Committee on the Control of Infectious Diseases.

CONYBEARE, E.T. (1964) Illnesses attributed to smallpox vaccination, 1951-1960. Monthly Bull. Minist. Hlth Publ. Hlth Lab. Serv. 23, 126 and 150.

Dick, G.W.A. (1962) Prevention of virus diseases in the community. Brit. med. J. ii, 1275.

Dixon, C.W. (1962) Vaccination against smallpox. Brit. med. J. i, 1262.

EDSALL, G. (1962) Efficacy of immunization procedures used in public health practice. Wld Hlth Org. Pbl. Hlth Papers No. 8, p. 51.

FreCkLeton, F.R. (1967) Federal government programs in immunization. Arch. environ. Hlth, 15, 512.

GregG, A. (1949) The golden gate of medicine. Ann. intern. Med. 30, 811.

KARZON, D.T. (1968a) Rationale for mumps vaccine usage. Proc. Fifth Annual Immunization Conference, San Diego, California, United States Public Health Service. 12 March, 1968.

KARzoN, K.T. (1968b) Simultaneous administration of live antigens. Proc. Fifth Annual Immunization Conference, San Diego, California, United States Public Health Service. 12 March, 1968.

KARZON, D.T. \& Henderson, D.A. (1966) Current status of live attenuated virus vaccines. Advanc. Pediat. 15, 121.

KEMPE, C.H. \& BENENSON, A.S. (1965) Smallpox immunization in the United States. J. Amer. med. Ass. 194, 161.

LenNon, R.G., Turnbull, C.D., Elsea, W.R., Karzon, D.T. \& WinkelsteIN, W., JR. (1967) Measles immunization in a northeastern metropolitan county. J. Amer. med. Ass. $200,815$.

MiLler, D.L. \& Galbraith, N.S. (1965) Surveillance of the safety of oral poliomyelitis vaccine in England and Wales 1962-4. Brit. med. J. ii, 504.

Ministry of Health (1955) Annual report of the Chief Medical Officer for the Year 1954., p. 66, H.M.S.O., London.

Ministry of Health (1963) Active immunisation against infectious disease (prepared by Standing Medical Advisory Committee). 
Ministry of Health (1964) Annual report of the Chief Medical Officer for the Year 1963, p. 170, H.M.S.O., London.

Ministry of Health (1967a). Annual Report of the Chief Medical Officer for the Year 1966, pp. 30 and 243, H.M.S.O., London.

MinistRY OF HEALTH (1967b) Memorandum on Vaccination Against Smallpox. Memo 312/MED, H.M.S.O.

Ministry of Health (1968a) Circular 29/68.

Ministry OF Health (1968b) Letter to General Practitioners and all Medical Officers of Health (England and Wales), G. E. Godber.

NefF, J.M., Lane, J.M., Pert, J.H., Moore, R., Millar, J. D. \& Henderson, D. A. (1967a) Complications of smallpox vaccination. I. National survey in the United States, 1963. New Engl. J. Med. 276.

NefF, J.M., Levine, R.H., LANe, J.M., Ager, E.A., Moore, H., Rosenstein, B.J., Millar, J.D. \& Henderson, D.A. (1967b) Complications of smallpox vaccination, United States, 1963. II. Results obtained by four statewide surveys. Pediatrics, 39, 916.

Preston, N. W. (1965) Effectiveness of pertussis vaccines. Brit. med. J. ii, 11

STRöm, J. (1960) Is universal vaccination against pertussis always justified? Brit. med. J. ii, 1184 .

United States Public Health Service (1967) Immunization Against Disease, 1966-67 (Prepared by Nationa Communicable Disease Center).

United States Public Health Service (1968a) Personal communication.

United States Public Health Service (1968b) Morbidity and Mortality Weekly Report, March 30.

United States Public Health Service (1968c) Morbidity and Mortality Weekly Report, June 8.

United States Public Health Service (1968d) Morbidity and Mortality Weekly Report, October. 